\title{
Высокоскоростные краевые разъемы 3М
}

\author{
С. Пескова ${ }^{1}$
}

УДК 621.37 | ВАК 05.27.01

\author{
Для решения проблемы соединения печатной платы с другими \\ элементами компания $3 \mathrm{M}$ предлагает инновационное комплексное \\ решение: высокочастотные краевые разъемы серии SPD08 и плоский \\ твинаксиальный кабель.
}

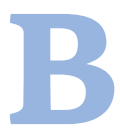

ысокоскоростные краевые разъемы SPD08 - это новейшая разработка компании 3М в области разъемов для стыковки печатных плат. Они предназначены для самого широкого круга применений: систем передачи данных, корпоративных серверов, телекоммуникационного оборудования, тестовых приборов и оборонной промышленности.

Разъемы SPD08 могут применяться в нескольких конфигурациях, например:

- мезонинная стыковка плат, требующая высокой скорости передачи данных (до 15 Гбит/с), высокой плотности монтажа, передачи сигналов с контролируемым импедансом;

- стыковка блоков плата-провод при сохранении скорости передачи данных до 25 Гбит / с.

\section{СИСТЕМА СОЕДИНИТЕЛЕЙ}

Система краевых разъемов SPD08 для SMT монтажа состоит из двух частей, которые обеспечивают мезонинную стыковку плат или соединение плата-плата с количеством контактов от 20 до 200 (рис. 1). В такой конфигурации разъемы зМ могут передавать сигналы с контролируемым уровнем импеданса на частотах до 15 Гбит / с на расстоянии стыковки 30 мм.

Корпус разъема, выполненный из пассивированного стеклом жидкокристаллического полимера, является великолепным термостабильным изолятором. $\mathrm{KoH}^{-}$ такты для поверхностного монтажа типа "крыло чайки" с шагом 0,8 мм удобны для эффективного и быстрого монтажа на производственных линиях. Два ряда медных контактов с покрытием позолотой экономят место на плате и упрощают ее разводку. Дополнительная опция защелки обеспечивает

ООО «Платан», начальник отдела маркетинга, svetlana@platan.ru. надежное соединение платы расширения (райзеркарты) с разъемом.

\section{СТЫКОВКА ПЛАТА-ПЛАТА}

Подпружинивающие контакты разъемов могут удерживать платы толщиной 1,57 мм ( $\pm 0,16$ мм) при минимальном усилии вставки. Контакты образуют классический краевой разъем на 2,54 мм.

Разъемы SPD08 предназначены для параллельной стыковки двух плат на высоте от 16 до 40 мм (рис. 2). Для этого используется стыковочная карта (riser card). Подключение такой карты допускает достаточную свободу при монтаже:

- сдвиг от края до края платы в вертикальной плоскости может достигать двух градусов;

- подвижность платы в плоскости "вперед-назад"по осям X-Y может составлять три градуса;

- конструкция контактов позволяет осуществлять монтаж "вслепую", при этом качество соединения не зависит от погрешности сдвига.

Такая свобода монтажа очень важна для приложений, где доступ к разъемам при ремонте или установке ограничен и приходится подключать плату практически «вслепую» (рис. 3).

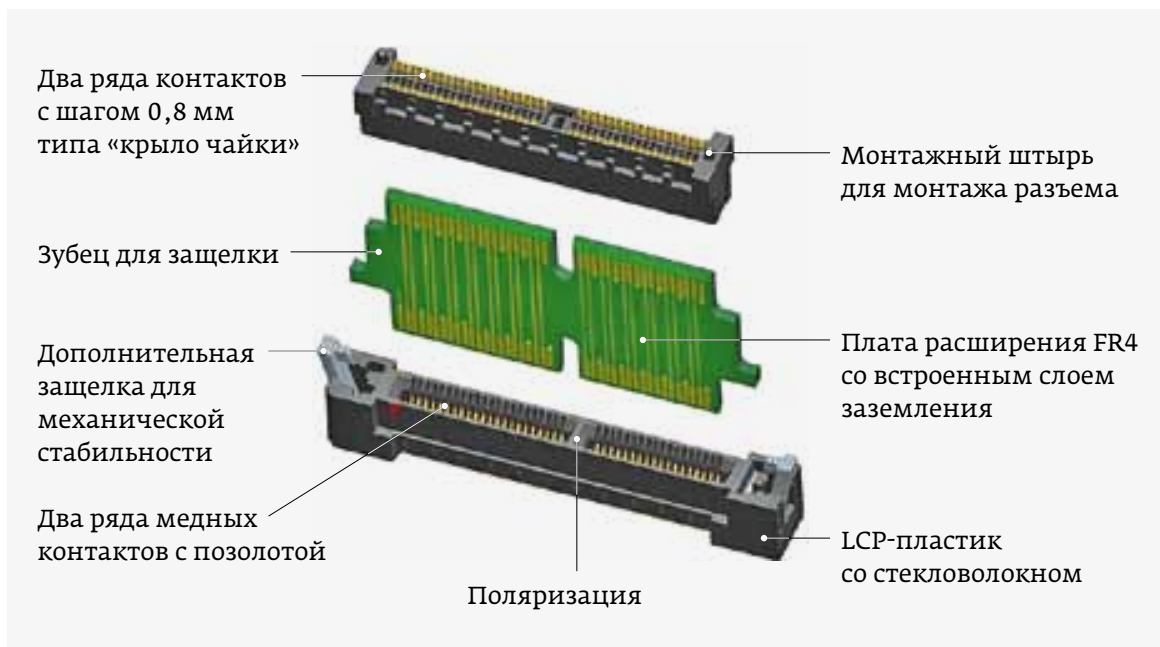

Рис. 1. Мезонинная стыковка плат с разъемами SPD08 


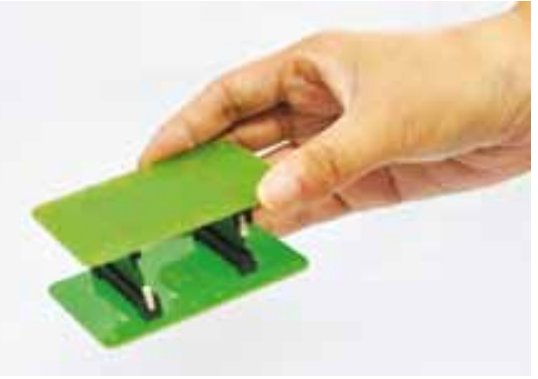

Рис. 2. Параллельная стыковка двух плат. Высота стыковки 16-40 мм
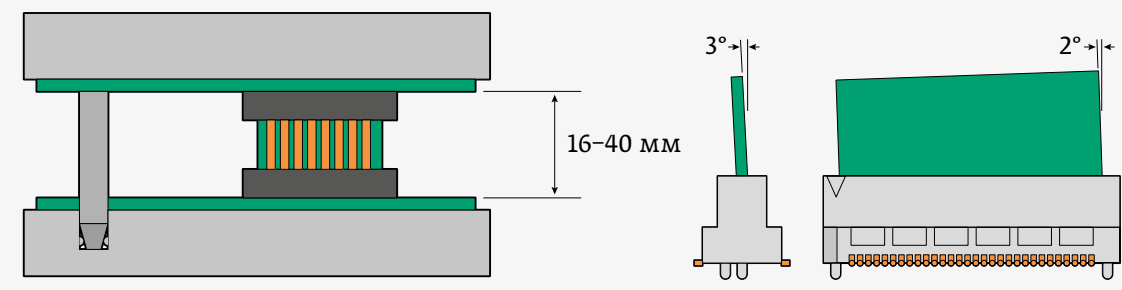

Рис. 3. Возможность монтажа практически "вслепую" (в труднодоступных местах)

\section{СТЫКОВКА ПЛАТА-КАБЕЛЬ}

Особые преимущества разъемов раскрываются при их использовании с уникальным твинаксиальным кабелем 3M (SL8800), когда скорость передачи данных может увеличиваться до 25 Гбит / с. Такой кабель отличается чрезвычайно малыми потерями и превосходной целостностью сигнала, при этом его гибкость ничем не ограничена, его можно сгибать под любым углом для экономичного размещения внутри блока (рис. 4). Плоская конструкция твинаксиального кабеля позволяет устранить ошибки подключения проводников и унифицирует монтаж. Контакты кабеля напрямую припаиваются к платепереходнику (рис. 5).

Контакты твинаксиального кабеля напрямую устанавливаются в разъем с платой, позолоченные ламели которой используются для подключения к краевому разъему (рис. 6). Угловое подключение такой кабельной сборки (90) обычно используется для протокола PCI Express. Для вертикальной стыковки применяются разъемы с защелками. Разъемы SPD08 производятся только с вертикальной ориентацией монтажа, угловое сочленение обеспечивается только через кабельную сборку.

\section{ПРИМЕНЕНИЕ КРАЕВЫХ РАЗЪЕМОВ SPD08}

Основная целевая сфера применения краевых разъемов SPD08 - это платы высокоскоростной передачи сигналов с минимальными потерями за счет контролирования импеданса сигналов. Это могут быть платы, поддерживающие XAUI, PCI Express (Gen 1/2/3), SATA и другие популярные последовательные интерфейсы.

Зависимость потерь передачи сигнала от частоты приведена на рис. 7 (минимальные потери на частоте 7,5 ГГц).

Такие высокоскоростные платы используются в следующих областях:

- телекоммуникационном сетевом оборудовании (базовые станции, роутеры, ключи);

- серверном оборудовании (сервера, блоки хранения данных, высокопроизводительные вычислительные кластеры);

- промышленной автоматизации (PLC/ PLD);

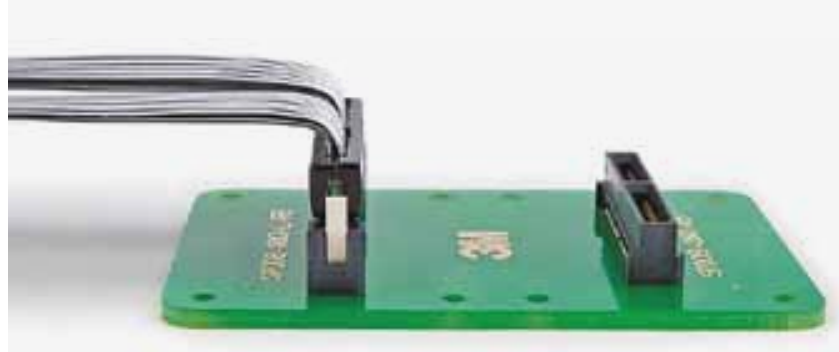

Рис. 4. Подключение твинаксиального кабеля под углом $90^{\circ}$ без потерь

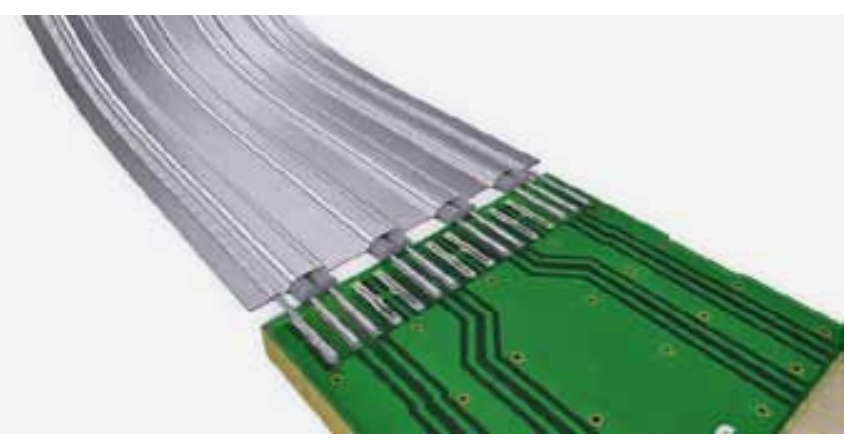

Рис. 5. Подключение твинаксиального кабеля к плате

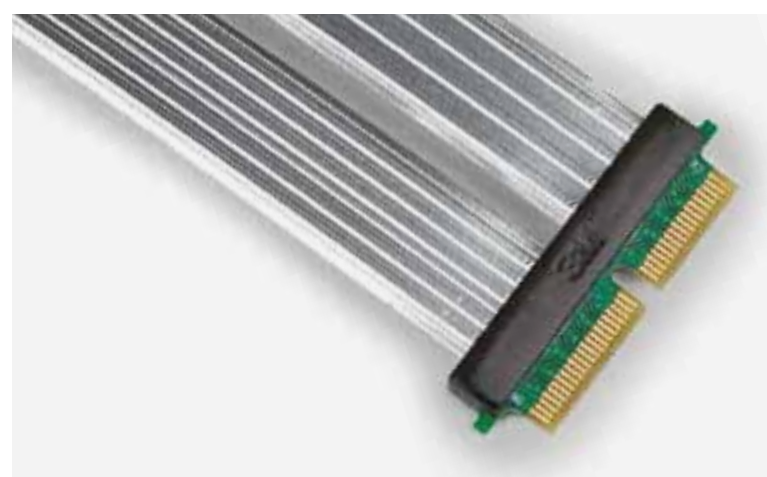

Рис. 6. Кабельная сборка с твинаксиальным кабелем 
- военной технике (COTS C4ISR);

- измерительном и тестовом оборудовании (газовой и жидкостной хроматографии).

\section{Технические характеристики:}

- материал контактов: медный сплав;

- покрытие контактов:

3-5 мкм - олово;

1,27 мкм - никель;

- материал корпуса:

LCР-пластик черный, UL 94V-0;

- материал защелки:

LCР-пластик бежевый,

UL 94V-0;

- ток контактов:

3 А при $30^{\circ} \mathrm{C}$ (один контакт);

0,5 А на контакт;

- сопротивление контактов: 50 мОм макс.;

- напряжение: 50 в;

- импеданс: для систем 85 или 100 Ом;

- скорость передачи: 7,5 ГГц (при -2 дБ вносимых потерь на стык 30 мм высотой);

- диапазон рабочих температур: $-55 . .125^{\circ} \mathrm{C}$

Система обозначений на разъеме показана на рис. 8.

\section{ОСНОВНЫЕ ПРЕИМУЩЕСТВА}

И ОСОБЕННОСТИ КРАЕВЫХ РАЗЪЕМОВ SPD08

\section{Поддержка высокоскоростных соединений} плата-плата:

- контролируемый импеданс, дизайн контактов ограничивает перекрестные помехи, поддержка скорости до 15 гбит / с (при высоте стека $30 \mathrm{mm);}$

\section{SPD08-020-L-RB-TR}

Упаковка

TR: на ленте

нет: поддон

Покрытие контактов

RB: $\quad 0,76$ мкм позолота

RA: 0,25 мкм позолота

Наличие защелки

L: с защелкой,

нет: без защелки

Количество контактов

020, 040, 060, 064, 080, 100, 120, 140, 160, 180, 200

Рис. 8. Обозначения на разъеме
- встроенная панель заземления ограничивает межрядные помехи и поддерживает целостность сигнала;

- поддержка XAUI, PCI Express (поколение 1/2/3), SATA и др.

\section{Различная высота стыка и прочность конструкции:}

- поддержка гибкой высоты стыка (в диапазоне 16-40 мм) благодаря применению промежуточной платы расширения;

- конструкция контактов позволяет осуществлять монтаж "вслепую", при этом качество соединения не зависит от погрешности сдвига (от края до края до двух градусов, вперед-назад до трех градусов)

\section{Миниатюрность и плотность монтажа:}

- шаг контактов 0,8 мм и их двурядное расположение экономят место на плате и упрощают развязку подключения.

\section{Широкий модельный ряд:}

- разъемы с количеством контактов от 20 до 200;

- модели с дополнительными защелками для прочной механической стыковки;

- нагрузка на контакт 0,5 А для смешанных и питающих сигналов.

\section{Широкая сфера применения:}

- реализация подключений провод-плата со скоростью 25 Гбит / с при использовании твинаксиального кабеля $3 \mathrm{M}$.

Более подробную информацию готов предоставить официальный дистрибьютор компании 3М по подразделению Interconnect Платан. www.platan.ru/3M/ 


\section{КНИГИ ИЗДАТЕЛЬСТВА "ТЕХНОСФЕРА»}

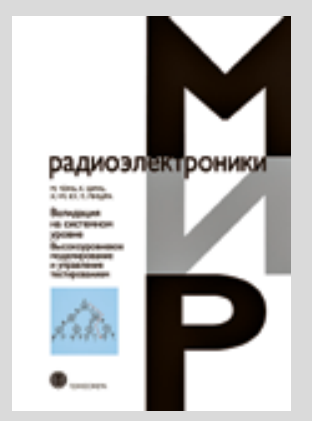

Цена 760 руб.

\section{ВАЛИДАЦИЯ НА СИСТЕМНОМ УРОВНЕ. ВЫСОКОУРОВНЕВОЕ МОДЕЛИРОВАНИЕ И УПРАВЛЕНИЕ ТЕСТИРОВАНИЕМ}

\author{
М. Чэнь, К. Цинь, Х.-М. Ку, П. Мишра \\ При поддержке $3 A O$ "СКАН" \\ Перевод с англ. под ред. А. Н. Ланцева
}

В этой книге описываются методы высокоуровневого моделирования и валидации комплексных систем аппаратных средств и программного обеспечения, включая архитектуры с многоядерными процессорами. Читатели узнают, как избежать затрат времени и ошибок при всесторонней системной валидации, в том числе при моделировании систем и их отказов, а также об автоматической генерации специализированных тестов и эффективных методиках валидации с использованием подобных тестов и подтверждения работоспособности систем. Методологии, описанные в этой книге, помогут разработчикам улучшить качество валидации благодаря выполнению тестов на ранних стадиях проектирования при одновременном снижении стоимости этих процессов и усилий, направленных на валидацию систем в целом.

Эта книга предназначена для студентов старших курсов, аспирантов, исследователей, разработчиков инструментов САПР, проектировщиков и менеджеров, заинтересованных в развитии эффективных инструментов и методов проектирования и валидации на системном уровне, генерации направленных тестов и функциональной валидации гетерогенных конструкций СнК.

\section{Разъемы} для передачи данных

- MDR разъемы с IDC наколкой на плоский кабель

- QSFP/SFP, SATA, miniSAS, PCI Express

- Разъемы карты памяти

- Кабельные сборки с твинаксиальным кабелем
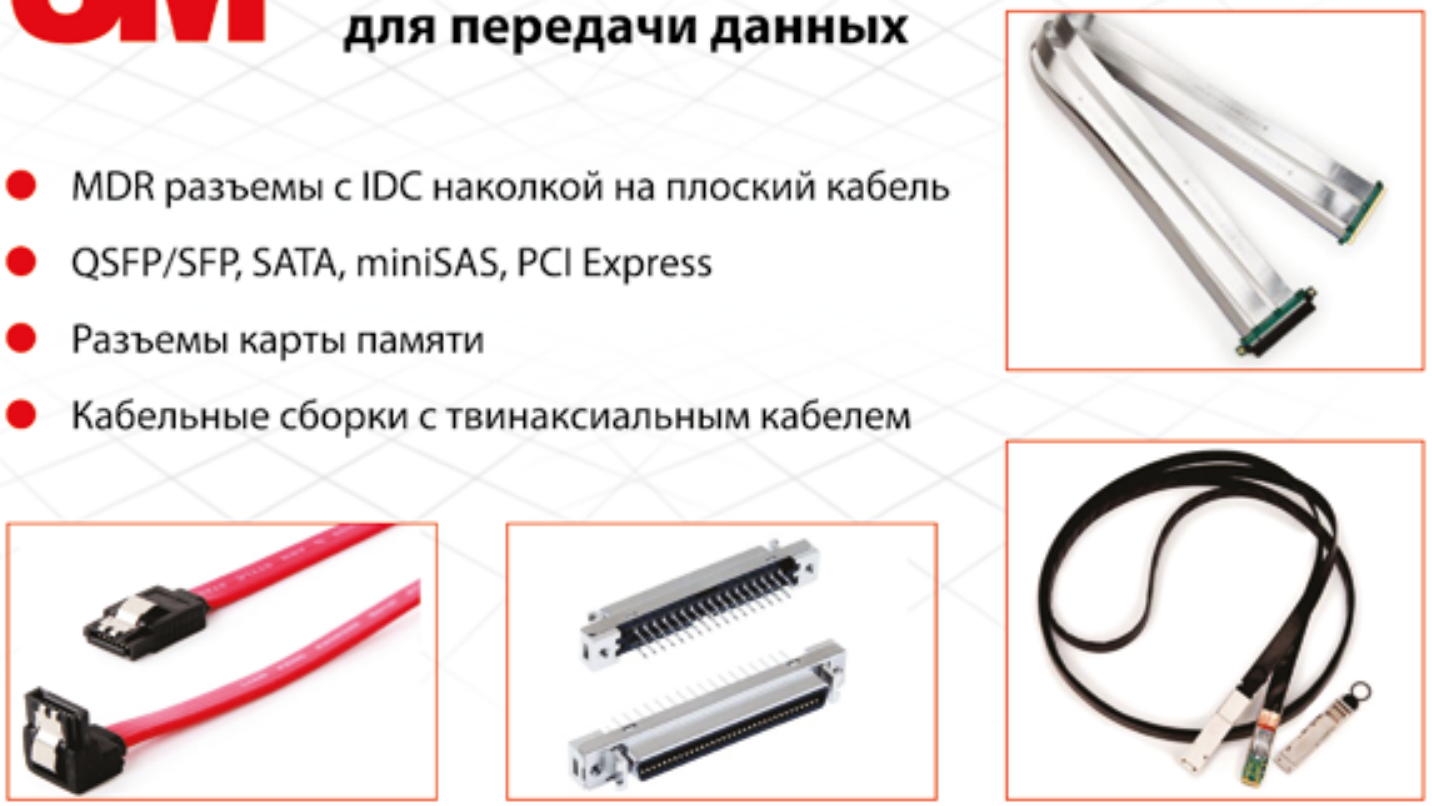

$\$$ TDK

Rourave

ROURENe

visHaY $^{\circ}$

Pelnol

3M

SICK

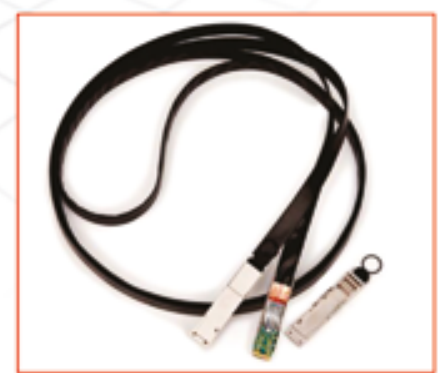

OSRAM

\section{다}

Panasonic

Jamıcon'

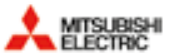

muRata 